\title{
THE ROLE OF MUSCLE ACTIVATION INDEX IN MOTOR CONTROL - A THEORETICAL PRESENTATION
}

\author{
Bogdan ANTOHE ${ }^{*}$, Marinela RAȚ $\breve{A}^{2}$, Gloria RAT, $\breve{A}^{2}$ \\ ${ }^{1}$ National University of Physical Education and Sports, Faculty of Physical Education and Sport, Bucharest, \\ Romania \\ 2 “Vasile Alecsandri” University of Bacău, Faculty of Movement, Sport and Health Sciences, Bacău, Romania \\ *Correspondence address: antohe_bogdan@yahoo.com
}

https://doi.org/10.35189/dpeskj.2020.59.1.3

\begin{abstract}
Motor control is the process by which the central nervous system regulates and coordinates muscular activity for the purpose of acquiring, learning and improving motor skills. Motor control has a hierarchical organization that starts from the peripheral sensory receptors (cutaneous, muscular, ligamentary), continues with the central sensory receptors in the spinal cord, which in turn terminate in the motor and premotor area at the level of the central nervous system. At the peripheral level, the mode of manifestation of the motor control system is achieved through the musculature, often in the form of muscle coactivation. Theoretically, muscle coactivation is presented as a process characteristic of all movements of the human body, resulting in the simultaneous contraction of two muscle groups (agonist-antagonist). The role of muscle coactivation is to improve the neuromuscular coordination, to increase the precision and stability of the movement. By calculating and knowing the value of the antagonist muscle contraction divided by the value of the agonist muscle contraction, the muscle activation index is determined. Being a qualitative assessment method of the motor control system, in performance sports, the calculation of the muscle coactivation index is particularly important because its values can provide valuable insights into the performance of athletes or the progress of the recovery process (when athletes are injured).
\end{abstract}

Keywords: coactivation, index, agonist, antagonist.

\section{Introduction}

Human movement is a complex, multifactorial process that occurs as a result of the interaction between the body and the environment in which it operates. In fact, movement is the result of actions to control the nervous system and all the structures form a joint (i.e. ligaments, tendons, muscles, fascicles, blood vessels, nerves, etc). The relationship between the environment and humans is achieved through the five analyzers, and of course through the neuro-myo-arthro-kinetic system, which is subordinated to the motor control system. As a concept, motor control appeared in 1967, when the Russian neuroscientist Nikolai Bernstein published the "hierarchical theory of motor control". Since then, motor control, whose role is to ensure relations between the central nervous system, the peripheral nervous system, the musculoskeletal system and the peripheral sensory receptors, has been studied more and more.

Motor control is the process through which the central nervous system (CNS) regulates and coordinates muscular activity for the purpose of acquiring, learning and improving motor skills (Abernethy et al., 1996, p. 196). Motor control has a hierarchical organization that starts from the peripheral sensory receptors (cutaneous, muscular, ligamentary), continues 
with the central sensory receptors in the spinal cord, which in turn terminates in the motor and premotor areas of the central nervous system. The interaction between the listed sensory receptors and the musculoskeletal system provides the possibility for motor control to manifest in the form of safe and complex motor acts. The analysis of the motor control can be done at two levels: neurophysiological (that emphasizes the role of anatomical structures in initiating and conducting movements, analyzing neuromuscular synergy and ordering hierarchy) and behavioural (intentional, programmed, goal feedback, efficiency feedback) (Epuran \& Stănescu, 2010, p. 106).

Because there is an indissociable anatomic and functional connection between the nervous system and the musculoskeletal system, the evaluation of skeletal muscle functionality can give us a true picture of how the body works in motion. One of the most used methods for assessing muscle function is surface electromyography. This is based on a non-invasive experimental technique, whose role is to seize and record the electrical signals produced by the skeletal muscles. Surface electromyography allows the study of the muscle activity both at rest and in motion (during the isometric or isotonic muscle contraction). The analysis of the muscle values recorded by surface electromyography is related to two muscles, the agonistantagonist groups. Any movement is based on the contraction action of one or more muscles, which can be agonist (i.e. producing movement) or antagonist (i.e. hindering movement). Therefore, motor control or motion control is the way to adjust movement and make dynamic adjustments to body posture. It essentially represents the control of the central nervous system over voluntary muscle activity. The degree of activation of the antagonist muscle relative to the degree of activation of the agonist muscle is called the coactivation index.

\section{Topic addressed}

\section{Agonist-antagonist muscle balance and muscle coactivation}

Along with the many traumatic conditions that occur in performance sports, the musculoskeletal system can experience countless muscle imbalances, whose values are not pathological, but functional. These can compromise the quality of the motor act. The causes of muscle imbalances can be numerous and diverse, but the most common ones are determined by the use of sports movements that involve more than one part of the body, inadequate warm-up of athletes, the existence of severe postural deficits, the selective strengthening of a single muscle group, etc. Early research on muscle activation was made in the 20th century by Sherrington (1909), who proposed the theory of mutual inhibition, according to which the agonist muscle contraction leads to reflex inhibition of the antagonist muscle. Over the years, based on Sherrington's law, researchers have begun to study in depth the phenomenon of muscle activation, which means the simultaneous action of the agonist and antagonist muscles at a certain point (Avramescu, 2013). The degree of muscle activation is one of the most useful parameters for the qualitative assessment of the neuromuscular function. It may be correlated with sports performance, the risk of injury or the recovery progress of injured athletes.

Cordun (1999, p. 41) states that the interaction between agonist and antagonist muscles increases the precision of the movement, especially since a larger number of muscles is involved. The degree of activation of the antagonist muscle differs depending on the motor 
task performed and, even if the movement is identical, the intensity of muscle contraction will always be different (Gorkovenko et al., 2012).

Kaminski et al. (2003) believe that muscle coactivation mainly plays an important role in the ligament protection, ensures homogenous compression on the joint surfaces and prevents them from overstressing. At the knee, the antagonist coactivation has the role of reducing the anterior tibia translation of the femur, thus reducing the risk of previous cross-ligament lesions (Wierzbicka \& Wiegner, 1996). Muscle coactivation has higher values during motor acts performed on unstable support surfaces (Aagard et al., 2000). Increasing the speed of movement and muscle fatigue do not prevent coactivation but influence the reduction of coordination between muscles (Kellis \& Kellis, 2001; Kellis, Zaferidis, \& Amiridis, 2011).

Because the stiffness of a joint is due to increased antagonist activation and increasing stiffness is important in fighting the joint instability, finding an optimal ratio between the degree of muscle activation and the movement performed is a difficult task for the central nervous system. If the degree of muscle activation is too high, we may have a decrease in performance of the muscular system by increasing the mechanical work done by the agonist muscle, which causes an overuse of the joint surfaces. If the degree of muscle activation is too low, joint stability will be diminished, predisposing the subjects to the risk of injury (Kellis et al., 2011). Although it was originally suggested that the degree of muscle coactivation would be generated by the central nervous system (Humprey \& Reed, 1983), it has now been demonstrated that muscle activation is in fact a response of the neuromuscular system to the information received from articular sensory receptors (Frey-Law \& Avin, 2014), which reinforces the idea that human movement is controlled on the basis of the feedback received from the peripheral sensory receptors. The increases in muscle strength gained at the end of the training periods are also generated by an improvement in the degree of activation of the antagonist muscle in relation to the agonist muscle. This aspect suggests that the strength developed by a joint is not only dependent on the strength generated by the agonist muscle but also on the inhibition of the antagonist muscle (Grabiner, 1985).

\section{Muscle coactivation index}

The muscle coactivation index (CI) is the way to measure the degree of muscle activation. In the last three decades, several computational formulations of the muscle coactivity index have been presented in the literature, based on the results obtained by subjects during the electromyographic assessments (Latash, 2018).

The importance of muscle coactivation for the qualitative parameters of the movement results from the fact that the decrease in value of the coactivation index produces:

- an increase in joint stability and the dynamic protection of ligaments;

- the improvement of motor control;

- increased muscle reaction time, etc. (Liebenson, 2007, p. 531).

Calculating muscle CI values requires concrete and accurate knowledge of the concepts of agonist and antagonist muscle. From a biomechanical point of view, the agonist muscle is the muscle that initiates a movement, while the antagonist muscle is that muscle that opposes agonist muscle contraction. It is generally believed that, when learning a new movement, the values of the muscle activation index are high, decreasing with improved motor control. 
The attempt to establish a standard assessment protocol that could be applied to all subjects was solved by using maximal muscle contraction values or average contraction values (recorded over several tenths of a second). Most of the times, the results are expressed as a percentage (from 0 to $100 \%$ ). The lower the percentage of muscle CI values, the better the ability of the muscular system to cope with more complex and harder motor tasks (Zuniga et al., 2018). The significant and unjustified increases in the muscle coactivation index values indicate the immaturity of the muscular system, and in subjects with chronic joint instability, the increase in muscle coactivation is considered a strategy adopted by the central nervous system in an attempt to increase joint stability (Masso et al., 2010).

\section{Formulas for calculating the muscle CI values}

The calculation of muscle CI values is done by using the data obtained through surface electromyography. In the current literature, we have found several computational formulas for the muscle CI values, but in most research studies, the most widely used formula is the one proposed by Falconer in 1985 and adapted by Kellis, Arabatzi and Papadopoulos (2003). Although this formula was proposed more than three decades ago, it is now the most commonly used equation to calculate the values of the muscle coactivation index, its efficiency being demonstrated by many research studies in which it was used: Nagai et al. (2012), Falconer and Winter (1985), Kellis, Arabatzi and Papadopoulos (2003) (Eq. 1).

The formula proposed by Kellis, Arabatzi \& Papadopoulos (2003) is as follows:

$\mathrm{CI}=\frac{2 \text { Iant }}{\text { Itotal }} * 100$

In the above formula, 2Iant and Itotal express the following:

- 2Iant represents the period of contraction of the antagonist muscle. For the calculation of 2Iant values, the following calculation formula is required:

Iant $=\sum_{\mathrm{t} 1}^{t 2}$ EMGtriceps surae $(\mathrm{t}) \Delta \mathrm{t}+\sum_{\mathrm{t} 2}^{\mathrm{t} 3}$ EMGtibial anterior $(\mathrm{t}) \Delta \mathrm{t}$

In this formula, the integrals $\mathrm{t} 1$ and $\mathrm{t} 2$ represent the period when the EMG values of the antagonist muscle (tibialis anterior) are lower than the EMG values of the agonist muscle (triceps surae), while the integrals $\mathrm{t} 2$ and $\mathrm{t} 3$ represent the period when the EMG values of the agonist muscle are lower than the EMG values of the antagonist muscle.

- Itotal is the integral of the sum of the electromyographic values of the antagonist and agonist muscles during the entire muscle activity and is calculated using the following formula:

$$
\text { Itotal }=\sum_{\mathrm{t} 1}^{t 3}[\text { EMGagon }+ \text { EMGantg }](\mathrm{t}) \Delta \mathrm{t}
$$




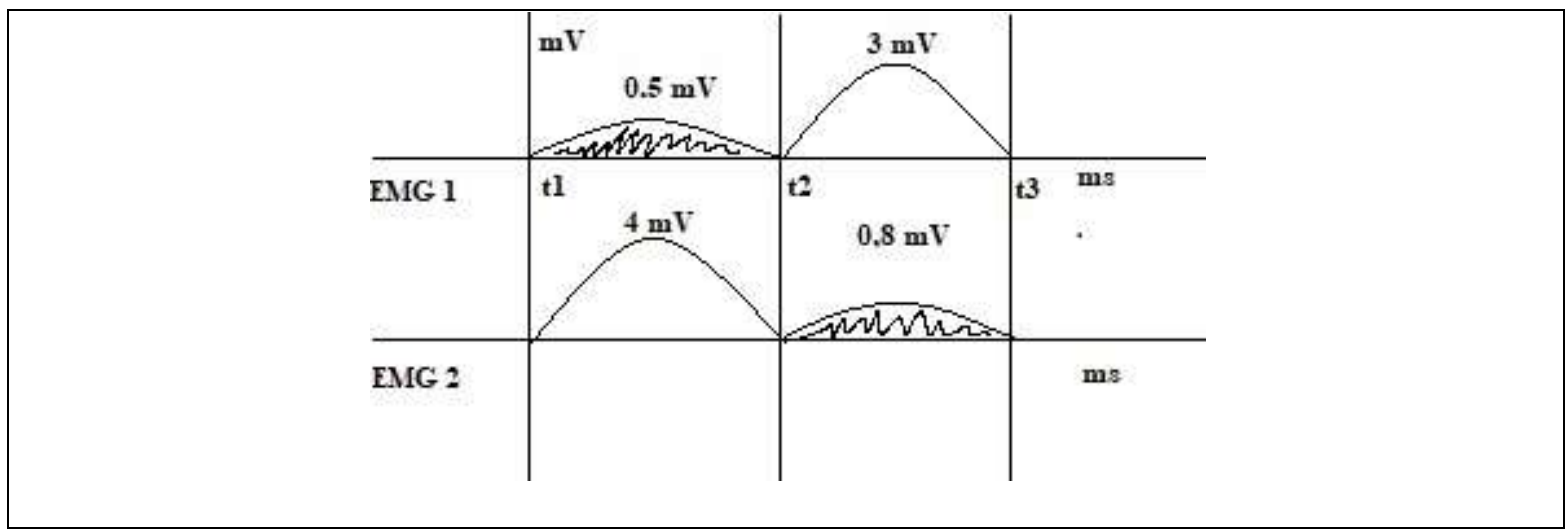

Note: $E M G=$ electromyography, $m V=$ millivolts, $m s=$ milliseconds, $t=$ time. The shaded area is the area of activity of the antagonist muscle. In order to obtain the muscle CI values for the above example, we will apply the formula as follows: CI = (2* $(0.5+0.8)) /$ $(0.5+3+4+0.8) * 100=31 \%$. The percentage obtained represents the degree of coactivation of the tibialis anterior muscle compared to the triceps surae muscle.

Figure 1. The schematic representation of the electromyographic wave and the method of calculating the muscle CI according to the formula proposed by Kellis, Arabatzi and Papadopoulos (2003)

In the literature, other CI calculation formulas are also proposed, such as those used by Ervilha et al. (2012) (Eq. 2), Zuniga et al. (2018), Lauer et al. (2013) (Eq. 3). These formulas are:

$\mathrm{CI}=2 * \frac{\text { EMGant }}{\text { EMGag+EMGant }} * 100$

$\mathrm{CI}=\frac{\text { EMGant }}{\text { EMGag }} * 100$

In order to calculate CI values in the ankle muscle during the plantar flexion movement, applying the formula for the agonist muscle action of the triceps surae and the antagonistic action of the tibialis anterior muscle is considered. In this situation, the triceps surae muscle is agonist, and the tibialis anterior muscle is antagonist. EMGant is the maximal electromyographic value recorded by the antagonist muscle, while EMGag is the maximal electromyographic value recorded by the agonist muscle. The results obtained by applying the three formulas are expressed in percentage.

However, we consider it most appropriate to use the formula proposed by Kellis, Arabatzi and Papadopoulos (2003), since these authors took into account the evolution of the electromyographic signal values over time.

\section{Research on the muscle activation index in sports activity}

Due to early technical limitations, most of the research aimed at calculating the muscle CI was related to a one-plane muscular system consisting of two muscle groups (agonistantagonist). Over time, research has been carried out attempting to highlight the degree of activation of several muscle groups, or rather muscle synergies, and it has been concluded that the calculations made by using algorithms can predict the occurrence of muscle synergies 
but only at a basic level of organization of the motor control system (Tresch, Cheung, \& d'Avella, 2006).

The muscle CI values were calculated at the elbow by Lauer et al. (2013) for swimmers, the authors demonstrating that the values of the muscle coactivation index can provide important information about the mechanical burden supported by the joint. Still at the elbow, Bazzucchi, Riccio and Felici (2008) assessed the muscle CI values for tennis players, demonstrating that athletes have lower values of the muscle coactivation index than those who do not practice tennis, especially the muscle groups involved in practising sports.

Research tracking the evolution of the muscle coactivation index following the application of balance/proprioceptive exercise programs is scarce, but what we have found demonstrates an improvement in muscle CI values through a balance-based recovery program for the elderly (Nagai et al., 2012). In addition, Rutkowska-Kucharska et al. (2018) obtained improvements in muscle CI values in gymnasts after applying some balance exercises, while Andrare et al. (2011) demonstrate that the closed kinetic chain exercises improve muscle CI values at the shoulder.

Regarding the changes in muscle CI values, increases have been demonstrated in third-age individuals (Nagai et al., 2013) and children (Grosset et al., 2008). In older people, increasing muscle CI values is considered a compensatory strategy for the motor control system, whose role is to increase joint stability, while in children, increasing muscle CI values denotes an immature motor control system. Alterations in the muscle CI have been reported in subjects with cerebral palsy or multiple sclerosis, therefore in people with neurological conditions.

Le et al. (2017) presented a table of research on the coactivation index (Table 1). From this table, we extracted the research relevant to the present work. In all the studies presented below, muscle CI values are calculated by the agonist-antagonist ratio. The interpretation of the results is based on the assumption that antagonist muscles have a lower contraction value compared to the lower contraction value of the agonist muscles. The results obtained are expressed as a percentage.

Table 1. Methods of calculating the muscle coactivation index presented in the literature (adapted after Le et al., 2017)

\begin{tabular}{|c|c|c|c|c|}
\hline Author & $\begin{array}{l}\text { Evaluated } \\
\text { anatomic } \\
\text { structure }\end{array}$ & $\begin{array}{c}\text { Muscle } \\
\text { activity } \\
\text { measurement } \\
\text { method } \\
\end{array}$ & CI calculation method & Interpretation of CI values \\
\hline $\begin{array}{l}\text { Falconer and } \\
\text { Winter } \\
(1984)\end{array}$ & $\begin{array}{l}\text { Lower } \\
\text { limb }\end{array}$ & EMG & $\begin{array}{l}\text { Area under the EMG } \\
\text { signal, agonist- } \\
\text { antagonist ratio }\end{array}$ & $\begin{array}{c}0-100 \%, \text { from the lowest value }(0 \%) \\
\text { to the highest value }(100 \%)\end{array}$ \\
\hline $\begin{array}{l}\text { Crenna et al. } \\
\text { (1992) }\end{array}$ & $\begin{array}{l}\text { Lower } \\
\text { limb }\end{array}$ & $\begin{array}{c}\text { EMG } \\
\text { normalized }\end{array}$ & $\begin{array}{l}\text { Area under the EMG } \\
\text { signal, agonist- } \\
\text { antagonist ratio }\end{array}$ & $\begin{array}{c}0-100 \%, \text { from the lowest value }(0 \%) \\
\text { to the highest value }(100 \%)\end{array}$ \\
\hline $\begin{array}{l}\text { Unnithan et } \\
\text { al. (1996) }\end{array}$ & $\begin{array}{l}\text { Lower } \\
\text { limb }\end{array}$ & $\begin{array}{c}\text { EMG } \\
\text { normalized }\end{array}$ & $\begin{array}{l}\text { Area under the EMG } \\
\text { signal, agonist- } \\
\text { antagonist ratio }\end{array}$ & $\begin{array}{c}0-100 \%, \text { from the lowest value }(0 \%) \\
\text { to the highest value }(100 \%)\end{array}$ \\
\hline $\begin{array}{l}\text { Granata et al. } \\
\qquad(2000)\end{array}$ & $\begin{array}{l}\text { Lower } \\
\text { limb }\end{array}$ & $\begin{array}{c}\text { EMG } \\
\text { normalized }\end{array}$ & $\begin{array}{l}\text { Area under the EMG } \\
\text { signal, agonist- } \\
\text { antagonist ratio }\end{array}$ & $\begin{array}{c}0-\infty \%, \text { from the lowest value }(0 \%) \\
\text { to } \infty \%\end{array}$ \\
\hline
\end{tabular}




\begin{tabular}{|c|c|c|c|c|}
\hline $\begin{array}{l}\text { Lamontagne } \\
\text { et al. (2000) }\end{array}$ & $\begin{array}{l}\text { Lower } \\
\text { limb }\end{array}$ & $\begin{array}{c}\text { EMG } \\
\text { normalized }\end{array}$ & $\begin{array}{l}\text { Area under the EMG } \\
\text { signal, agonist- } \\
\text { antagonist ratio }\end{array}$ & $\begin{array}{c}0-\infty \%, \text { from the lowest value }(0 \%) \\
\text { to } \infty \%\end{array}$ \\
\hline $\begin{array}{l}\text { Rudolph et } \\
\text { al. (2000) }\end{array}$ & $\begin{array}{l}\text { Lower } \\
\text { limb }\end{array}$ & $\begin{array}{c}\text { EMG } \\
\text { normalized }\end{array}$ & $\begin{array}{l}\text { Agonist-antagonist ratio, } \\
\text { reported to the } \\
\text { contraction period }\end{array}$ & $\begin{array}{c}0-200 \%, \text { from the lowest value }(0 \%) \\
\text { to the highest value }(200 \%)\end{array}$ \\
\hline $\begin{array}{l}\text { Kellis et al. } \\
\text { (2003) }\end{array}$ & $\begin{array}{l}\text { Lower } \\
\text { limb }\end{array}$ & $\begin{array}{c}\text { EMG } \\
\text { normalized }\end{array}$ & $\begin{array}{l}\text { Area under the EMG } \\
\text { signal, agonist- } \\
\text { antagonist ratio }\end{array}$ & $\begin{array}{c}0 \%=\text { flexor muscles are not active } \\
50 \%=\text { maximum coactivation, } \\
100 \%=\text { extensors are not active }\end{array}$ \\
\hline $\begin{array}{l}\text { Don et al. } \\
(2007)\end{array}$ & $\begin{array}{l}\text { Lower } \\
\text { limb }\end{array}$ & $\begin{array}{c}\text { EMG } \\
\text { normalized }\end{array}$ & $\begin{array}{l}\text { Agonist-antagonist ratio, } \\
\text { reported to the } \\
\text { contraction period }\end{array}$ & $\begin{array}{c}0-100 \%, \text { from the lowest value }(0 \%) \\
\text { to the highest value }(100 \%)\end{array}$ \\
\hline $\begin{array}{l}\text { Bautmans et } \\
\text { al. (2011) }\end{array}$ & $\begin{array}{l}\text { Upper } \\
\text { limb }\end{array}$ & $\begin{array}{c}\text { EMG } \\
\text { normalized }\end{array}$ & Agonist-antagonist ratio & $\begin{array}{c}0-100 \%, \text { from the lowest value }(0 \%) \\
\text { to the highest value }(100 \%)\end{array}$ \\
\hline $\begin{array}{l}\text { Cheng et al. } \\
(2008,2014)\end{array}$ & $\begin{array}{l}\text { Cervical } \\
\text { spine }\end{array}$ & $\begin{array}{c}\text { EMG } \\
\text { normalized }\end{array}$ & Agonist-antagonist ratio & $\begin{array}{c}0-100 \%, \text { from the lowest value }(0 \%) \\
\text { to the highest value }(100 \%)\end{array}$ \\
\hline
\end{tabular}

Note: $C I=$ coactivation index, $E M G=$ electromyography.

\section{Conclusion}

Through muscle activation, motor control makes it possible to manage postural deviations during sports activities. The degree of muscle coactivation is expressed as a percentage using the calculation formula of the muscle coactivation index. We consider the muscle coactivation index an important parameter with a particular role in motor control, which gives us indications about the athlete's functional abilities during the training period or after suffering an injury. We make this statement because there is often the possibility that the muscle force is maximal, and the values of the muscle coactivation index are diminished. Finding an optimal ratio between the quantitative (muscle strength) and qualitative parameters (muscle activation index) can be of real help in improving sports performance and preventing injuries.

\section{References}

Aagaard, P., Simonsen, B., Andersen, J., Magnusson, S., Bojsen-Møller, F., \& DyhrePoulsen, P. (2000). Antagonist muscle coactivation during isokinetic knee extension. Scandinavian Journal of Medicine \& Science in Sports, 10(2), 58-67. DOI: 10.1034/j.1600-0838.2000.010002058.x

Abernethy, B., Hanrahan, S., Kippers, V., Mackinnon, L., \& Pandy, M. (1996). The Biophysical foundations of human movment ( $2^{\text {nd }}$ ed.). Australia: Macmillan Education.

Andrare, A., Araujo, R., Tucci, H., Martins, J., \& Oliveria, A. (2011). Coactivation of the shoulder and arm muscles during closed kinetic chain exercises on an unstable surface. Singapore Medicine Journal, 52(1), 35-41. PMID: 21298239

Avramescu, T. (2013). Analiza mişcării umane. Glosar de termeni medicali [Analysis of human movement. Glossary of medical terms]. Retrieved from http://orthoeman.ro/ro/data/_uploaded/file/ortho-eman-glosar_medical\%2Btehnic-RO.pdf

Bazzucchi, I., Riccio, M., \& Felici, F. (2008). Tennis players show a lower coactivation of the elbow antagonist muscles during isokinetic exercises. Journal of Electromyography and Kinesiology, 18(5), 752-759. DOI: 10.1016/j.jelekin.2007.03.004 
Bernstein, N. (1967). The co-ordination and regulation of movements. Oxford: Pergamon Press.

Cordun, M. (1999). Kinetologie medicală [Medical kinetology]. Bucureşti: Axa.

Epuran, M., \& Stănescu, M. (2010). Invățtare motrică - aplicații în activități corporale [Motor learning - applications to bodily activities]. Bucureşti: Discobolul.

Ervilha, U., Farina, D., Arendt-Nielsen, L., \& Graven-Nielsen, T. (2005). Experimental muscle pain changes motor control strategies in dynamic contractions. Experimental Brain Research, 164, 215-224. https://doi.org/10.1007/s00221-005-2244-7

Falconer, K., \& Winter, D. (1985). Quantitative assessment of co-contraction at the ankle joint in walking. Electromyography Clinical Neurophysiology, 25, 135-149. PMID: 3987606

Frey-Law, L., \& Avin, K. (2013). Muscle coactivation: A generalized or localized motor control strategy? Muscle nerve, 48(4), 578-585. doi: 10.1002/mus.23801

Grabiner, M. D. (1985). Maximum rate of force development is increased by antagonist conditioning contraction. Journal of Applied Kinesiology, 77(2), 807-811. DOI: 10.1152/jappl.1994.77.2.807

Gorkovenko, A., Sawczyn, S., Bulgakova, N., Jasczur-Nowicki, J., Mishchenko, V., \& Kostyukov, A. (2012). Muscle agonist-antagonist interactions in an experimental joint model. Experimental Brain Research, 222(4), 399-414. doi: 10.1007/s00221-012-3227-0

Grosset, J., Mora, I., Lambertz, D., \& Pérot, C. (2008). Voluntary activation of the triceps surae in prepubertal children. Journal of Electromyography and Kinesiology, 18, 455-465. DOI: 10.1016/j.jelekin.2006.11.002

Humprey, D., \& Reed, D. (1983). Separate cortical systems for control of joint movement and joint stiffness: Reciprocal activation and coactivation of antagonist muscles. Advances in Neurology, 39, 347-372. PMID: 6419553

Kaminski, T., Buckley, B., Powers, M., Hubbard, T., \& Ortiz, C. (2003). Effect of strength and proprioception training on eversion to inversion strength ratios in subjects with unilateral functional ankle instability. British Journal of Sports Medicine, 37, 410-415. doi: 10.1136/bjsm.37.5.410

Kellis, E., Arabatzi, F., \& Papadopoulos, C. (2003). Muscle co-activation around the knee in drop jumping using the co-contraction index. Journal of Electromyography and Kinesiology, 13, 229-238. DOI: 10.1016/S1050-6411(03)00020-8

Kellis, E., \& Kellis, S. (2001). Effects of agonist and antagonist muscle fatigue on muscle coactivation around the knee in pubertal boys. Journal of Electromyography and Kinesiology, 11, 307-318. DOI: 10.1016/S1050-6411(01)00014-1

Kellis, E., Zaferidis, A., \& Amiridis, I. (2011). Muscle coactivation before and after the impact phase of running following isokinetic fatigue. Journal of Athletic Training, 46(1), 11-19. doi: 10.4085/1062-6050-46.1.11

Lauer, J., Figueiredo, P., Vilas-Boas, J., Fernandes, R., \& Rouard, A. (2013). Phasedependence of elbow muscle coactivation in front crawl swimming. Electromyography and Kinesiology, 23(4), 820-825. doi: 10.1016/j.jelekin.2013.02.004

Latash, M. (2018). Muscle coactivation: Definitions, mechanisms, and functions. Journal of Neurophysiolgy, 120(1), 88-104. https://doi.org/10.1152/jn.00084.2018

Le, P., Best, T., Khan, S., Mendel, E., \& Marras, W. (2017). A review of methods to assess coactivation in the spine. Journal of Electromyograpphy and Kinesiology, 32, 51-60. doi: 10.1016/j.jelekin.2016.12.004

Liebenson, C. (2007). Rehabilitation of the spine. A practitioner's manual. Philadelphia: Lippincott Williams \& Wilkins. 
Masso, N., Rey, F., Romero, D., Gual, G., Costa, L., \& German, A. (2010). Surface electromyography applications in the sport. Apunts Medicina de l'Esport, 45(165), 121130. DOI: $10.5772 / 56167$

Nagai, K., Yamada, M., Tanaka, B., Uemura, K., Mori, S., Aoyama, T., ... Tsuboyama, T. (2012). Effects of balance training on muscle coactivation during postural control in older adults: a randomized controlled trial. The Journals of Gerontology: Series A, 67(8), 882889. doi: $10.1093 /$ gerona/glr252

Nagai, K., Yamada M., Mori, S., Tanaka, B., Uemura, K., \& Aoyama, T. (2013). Effect of the muscle coactivation during quiet standing on dynamic postural control in older adults. Gerontology and Geriatrics, 56, 129-133. doi: 10.1016/j.archger.2012.08.009

Rutkowska-Kucharska, A., Szpala, A., Jaroszczuk, S., \& Sobera, M. (2018). Muscle coactivation during stability exercises in rhythmic gymnastics: A two-case study. Applied Bionics and Biomechanics, 2018(1), 1-8. doi:10.1155/2018/8260402

Sherrington, C. S. (1909). Reciprocal innervation of antagonistic muscles. Fourteenth note on double reciprocal innervation. Proceedings of the Royal Society B: Biological Sciences, 81(548), 249-268. doi:10.1098/rspb.1909.0022

Tresch, M., Cheung, V., \& d'Avella, A. (2006). Matrix factorization algorithms for the identification of muscle synergies: Evaluation on simulated and experimental data sets. Journal of Neurophysiology, 95(4), 2199-212. DOI: 10.1152/jn.00222.2005

Wierzbicka, M., \& Wiegner, A. (1996). Accuracy of motor responses in subjects with and without control of antagonist muscle. Journal of Neurophysiology, 75(6), 2533-2541. DOI: $10.1152 /$ jn. 1996.75.6.2533

Zuniga, J., Dimitrios, K., Peck, J., Srivastava, R., Pierce, J., Dudley, D., ... Knar, B. A. (2018). Coactivation index of children with congenital upper limb reduction deficiencies before and after using a wrist-driven 3D printed partial hand prosthesis. Journal of NeuroEngineering and Rehabilitation, 15(1), 48. doi: 10.1186/s12984-018-0392-9 